\title{
The physician assistant hospitalist: a time-motion study
}

\author{
Julia V. Beresford ${ }^{* 1}$, Roderick S. Hooker ${ }^{2}$ \\ ${ }^{1}$ Director International Program, Johns Hopkins Medicine International, All Children's Hospital, United States \\ ${ }^{2}$ Health Policy Consultant, United States
}

Received: June 8, 2015

Accepted: July 1, 2015

Online Published: July 14, 2015

DOI: $10.5430 /$ jha.v4n5p61

URL: http://dx.doi.org/10.5430/jha.v4n5p61

\begin{abstract}
Objective: The role of hospital-based physician assistants (PAs) is in need of delineation. To learn more about their activities, an administrative research project compared the tasks of hospitalists. In this setting an MD-PA team managed the adult medicine ward each weekday while three MDs rotated shifts.

Methods: A priori a survey of hospitalist activities was administered to four providers in a medium sized hospital (3 MDs and 1 PA). This was followed by time-motion documentation that involved shadowing each member of the MD-PA hospitalist teams over a three-month period. A univariate analysis of activity patterns (perceived and observed) assessed what was perceived and what actually occurred on the wards. The mean, standard deviation, and difference in means for each task were calculated.

Results: In the survey the PA reported she spent one-half of her hospitalist workdays on direct patient care and the physicians spent less time on direct patient care. Physicians believed they spent half days on direct patient care and believed the PA spent less time on direct patient care than they did. In the time-motion study shadowing the four hospitalists separately what was observed was that the PA spent $18 \%$ of her workday on direct patient care and $54 \%$ on indirect patient care - primarily patient encounter documentation. The three physicians spent $15 \%$ of their workday on direct patient care and $54 \%$ on indirect patient care - primarily patient encounter documentation. In summary, the perception of what each provider thought they did and what they in fact did differed significantly when actually observed. All four hospitalists (regardless of team composition) spent less than $20 \%$ of their workday with patients, and the rest divided among documentation, examination and test results, hospital meetings, and breaks. Task activity was similar for all providers except MDs attended more administrative meetings than the PA.

Conclusions: The perception that physicians have of PA roles and what a PA actually does has been a reoccurring observation. A lack of understanding of PA role delineation by physicians may contribute to employment reluctance.
\end{abstract}

Key Words: Task shifting, Physician assistant, Hospitalist, Role delineation, Territorial hospital, St. Croix

\section{INTRODUCTION}

Since the turn of the century shortages have become particularly acute in rural and remote areas in North America as fewer physicians choose to provide medical services in such locations. ${ }^{[1]}$ Workforce shortages in low-density areas are predicted to further reduce the already-limited services pro- vided by public health agencies. ${ }^{[2]}$ One solution to address the shortage is that of task shifting. Task shifting (i.e., moving activities from one set of providers to another) permits physicians to delegate routine patient care functions to physician assistants (PAs) and nurse practitioners (NPs). Little is known about how much a physician can delegate to a PA or

\footnotetext{
${ }^{*}$ Correspondence: Julia V. Beresford; Email: jberesf1@jhmi.edu; Address: Director International Program, Johns Hopkins Medicine International, All Children's Hospital, $5016^{\text {th }}$ Ave S, St. Petersburg, United States.

Published by Sciedu Press 
NP in a hospitalist team arrangement.

Administrators of urban hospitals have incorporated PAs to help solve workforce shortages for a couple decades. Such activity has provided some data regarding the output, quality, and productivity of large hospitals. ${ }^{[3]}$ What little is known about small, rural hospitals has been based on the reports about the productivity of physicians and PA/NPs but little beyond that. Almost nothing is known about the productivity of physician hospitalists when a PA/NP is introduced to the staffing mix or when they are used in remote locations such as frontier counties, small provincial towns, and territorial islands.

\section{Objective}

In 2012 the medical department of the hospital on St. Croix decided to employ a PA as a hospitalist to offset the increasing demand for physician services. None of the medical staff had experience working with a PA, and the literature was absent in describing hospital PA roles. This new employment provided an opportunity to observe a PA functioning as a hospitalist in a remote and isolated situation. An administrative research study on hospitalist roles was initiated.

\section{Methods}

\subsection{Study setting}

The location was the Governor Juan F. Luis Hospital \& Medical Center on St. Croix Island in the western Caribbean. St. Croix is one of four US Virgin Islands and is the eastern-most part of the US and residence for 50,601 inhabitants. At the time of the study, the hospital employed approximately 600 personnel and averaged 4,000 admissions per year. Clinical facilities ranged from newborn services to dialysis and psychiatric treatment. Surgical services included urology, plastics, otolaryngology, and spine surgery. In-patient coverage by hospitalists is provided by physicians and PAs Monday Friday, 8 AM to 5 PM and did not include any house staff.

The average daily census of 65 patients was split amongst the three physicians and one PA. The PA operated independently with oversight provided by the supervising physicians including co-signatures of notes and ancillary orders. The PA was not individually assigned to any one group of patients and instead rounded on all patients admitted to the medicine service as one of two hospitalists each day. Billing for services rendered was only applicable for the physician, as the hospital was not billing for services by the PA due to the legislative policy of the Virgin Islands.

Any PA's scope of practice in the Virgin Islands is limited due to the supervising relationship. In addition, a lack of autonomy and no prescriptive privileges further reduces their practice abilities. Scope of practice is granted via Virgin Islands legislation with additional limitations placed by the credentialing facility.

\subsection{Study design}

The two-phase study consisted of a pre-test survey on daily patient tasks, an observation period, followed by an assessment. A quantitative observational time-motion case study of hospitalist clinicians was determined by committee consensus as the best means of capturing the activities of hospitalist physicians and PAs in the absence of any published data. The object was to identify physician and PA productivity and potential sources of efficiency when working in complex hospital environments. This technique was selected from health services research studies as the best way to document daily labor activity. ${ }^{[4]}$

\subsubsection{Self-report of hospital time spent}

A self-report questionnaire was developed a priori to query how the participant hospitalists perceived their time spent in different job functions. Job functions were organized by specific tasks. The instrument allowed providers to note the amount of time they believed they spent on each function or task on average.

\subsubsection{Time-motion scorecard}

A list of daily activities of physicians in hospital roles was adapted from Weigel, et al. ${ }^{[5]}$ The time-motion scorecard was further refined following a pilot study of time-motion observation with each practitioner.

\subsubsection{Observations (time-motion)}

Each observation period was a half day (4 hours). Half day periods were stratified and then randomly selected to ensure each of the four hospitalists were observed equally. The observer maintained a minimum of 3 meters distance from any provider activity, usually more, with a scorecard and stopwatch discretely concealed to minimize the observerobserved effect. Because the observer was a hospital administrator, her presence on the ward was routine and did not draw attention. Activities were encoded for every unique activity, as well as every 5 minutes regardless of activity, and time rounded to the nearest 30 seconds or at the onset of a new activity. All activities during the observation period, including those outside the ward, were documented.

\subsection{Statistical analysis}

For each hour shadowed, the total time each study participant spent in each of the task categories was recorded in minutes. Descriptive, univariate statistics were generated, including the time in minutes spent on each task category per half day, the standard deviation, and the percentage of the half day

ISSN 1927-6990 E-ISSN 1927-7008 
spent on each task for each clinician, as well as among the three physicians in the time-motion study. Time spent on each task per half day for each clinician was compared to the self-reported tasks collected through the questionnaire. The mean, standard deviation, and difference in means for each task were calculated. In the same way, physician estimates of how PAs spent their time were compared to PA time-motion data, and vice versa. The University of Phoenix approved the study protocol.

\section{RESULTS}

The researcher shadowed each physician (MD) or PA for 4 hours a day for a total of 20 hours for each provider; 80 hours of observation spread over the months of June through August 2012 between the hours of 8 AM and 5 PM weekdays.

\subsection{Comparison of perceived time spent on selected tasks}

Preceding the observation the PA estimated spending onehalf $(52 \%)$ of her time on direct patient care and, collectively, the physicians estimated they spent $39 \%$ on direct patient care (see Table 1). Indirect patient care was $30 \%$ of the tasks for the PA reviewing herself; in reviewing the physicians, she thought the same (29\%). The PA estimated that the physicians spent $19 \%$ of their day on personal tasks and $13 \%$ of the day on miscellaneous tasks. Similarly, the PA reported she believed she spent $12 \%$ on personal tasks and only $5 \%$ on miscellaneous tasks. From the self-report, the PA believed she spent $13 \%$ more time on direct patient care tasks and $15 \%$ less time on miscellaneous and personal tasks than a physician. The PA marked that physicians spent more time on meetings and communications than she did.

The physicians estimated (in the aggregate) that they spent one-half of their days on direct patient care and the PA spent less time. They believed the PA spent more time on indirect patient care than they did (see Table 1). All of the physicians believed the PA spent $11 \%$ less time on direct patient care tasks and $13 \%$ more time on indirect patient care than they did. The MDs also marked more time spent on meetings as compared to a PA. None of the physicians noted that they spent any time on the categories of teaching and professional development. Neither the PA nor physicians agreed on the proportion of time they believed was spent on direct and indirect patient care by the other provider. In summary, each participant believed that they spent a larger percentage of time on direct patient care than the other provider.

Table 1. Self-Report findings of how time is spent by each provider and how they perceive the other provider(s)

\begin{tabular}{|c|c|c|c|c|c|}
\hline \multirow{2}{*}{ Task } & \multicolumn{2}{|c|}{ Review of Self (\%) } & \multicolumn{2}{|c|}{ Review of Other Provider (\%) } & \multirow{2}{*}{$\begin{array}{c}\text { Difference (\%) } \\
\text { Means }\end{array}$} \\
\hline & Means & $S D$ & Means & $S D$ & \\
\hline \multicolumn{6}{|l|}{ Physicians ( $\mathbf{N}=3)$} \\
\hline Direct Patient Care & 49.3 & 12.8 & 38.2 & 2.4 & 11.1 \\
\hline Indirect Patient Care & 29.7 & 4.5 & 42.6 & 4.2 & -12.9 \\
\hline Personal & 10.5 & 2.4 & 13.8 & 2.3 & -3.3 \\
\hline Miscellaneous & 10.5 & 8.9 & 5.5 & 3.5 & 5 \\
\hline \multicolumn{6}{|c|}{ Physician Assistant $(\mathrm{N}=1)$} \\
\hline Direct Patient Care & 51.6 & - & 38.7 & - & 12.9 \\
\hline Indirect Patient Care & 31.5 & - & 29 & - & 2.5 \\
\hline Personal & 12.1 & - & 19.4 & - & -7.3 \\
\hline Miscellaneous & 4.8 & - & 12.9 & - & -8.1 \\
\hline
\end{tabular}

\subsection{Time-motion data}

The time-motion observations consisted of tasks grouped into five categories: Direct Patient Care, Indirect Patient Care, Education, Personal, and Miscellaneous. Indirect patient care was admitting, discharge, daily charting, reviewing tests and procedure results, and communicating about the patient.

All observations of the four hospitalists were grouped by the categories listed in Table 2. Percentages were computed for the time the providers spent in each category during the half day observed. If a task was not performed during that observation period, the data point recorded was zero. After the data points were grouped into predefined categories, the Published by Sciedu Press mean and standard deviations were computed for the percentage of time spent on each task. The difference in means was also computed.

The PA spent $18 \%$ on direct patient care. More than half $(54 \%)$ of her time was on indirect patient care and the majority of this time was spent on patient encounter documentation. She spent $28 \%$ of her time on education (includes professional development and teaching), personal tasks, and miscellaneous tasks. The tasks recorded most often for the PA were documentation, examinations, procedures, and followup. Family meetings and writing orders were recorded least often. 
Table 2. Time-motion observations of physician assistant and physicians

\begin{tabular}{|c|c|c|c|c|c|}
\hline \multirow{2}{*}{ Task } & \multicolumn{2}{|c|}{ Physician Assistant (\%) } & \multicolumn{2}{|c|}{ Physicians (\%) } & \multirow{2}{*}{$\begin{array}{c}\text { Difference (\%) } \\
\text { Means }\end{array}$} \\
\hline & Means & $S D$ & Means & $S D$ & \\
\hline Direct patient care (\%) & 17.9 & 11.1 & 15.1 & 5.5 & 2.8 \\
\hline Exams, procedures, and follow-up & 17.5 & 11 & 13.2 & 5.6 & 4.3 \\
\hline Family meetings & 0.4 & 0.8 & 1.9 & 2.7 & -1.5 \\
\hline Indirect patient care (\%) & 54.2 & 23.2 & 54.4 & 19.1 & -0.2 \\
\hline Documentation & 32.2 & 16.4 & 31.9 & 10.8 & 0.4 \\
\hline Reviewing results & 6.7 & 5.1 & 3.5 & 5 & 3.2 \\
\hline Communications & 13.3 & 4.6 & 14.5 & 8.7 & -1.2 \\
\hline Writing orders & 2 & 1.9 & 4.5 & 5 & -2.5 \\
\hline Education (\%) & 7.4 & 16.5 & 15.3 & 23.3 & -7.9 \\
\hline Professional development & 5.9 & 13.1 & 15.3 & 23.3 & -7.9 \\
\hline Teaching & 7.4 & 16.5 & 15.3 & 23.3 & -7.9 \\
\hline Personal (\%) & 8.2 & 17 & 2.2 & 2.3 & 6 \\
\hline Bathroom breaks and meals & 8.2 & 17 & 2.2 & 2.3 & 6 \\
\hline Miscellaneous (\%) & 12.3 & 7.5 & 13 & 10.4 & -0.7 \\
\hline Obtaining medical supplies & 12.3 & 7.5 & 13 & 10.4 & -0.7 \\
\hline
\end{tabular}

The three MDs spent $15 \%$ on direct patient care. Indirect patient care tasks were $54 \%$ of their workday and the majority of this time was spent on documentation. Educational tasks, personal tasks, and miscellaneous tasks were one-tenth of the day. Documentation and professional development tasks were recorded most often for the physicians.

Table 3 shows physicians spent $10 \%$ more time on profes- sional development tasks and 8\% more time on teaching compared to the PA. The PA spent $6 \%$ more time on personal tasks and $4 \%$ more time on exams, procedures, and follow-up tasks. Between the provider types, indirect patient care only differed by $0.2 \%$ and direct patient care differed by $3 \%$. For all providers, daily breaks for errands, meals, and toilet were $12 \%-13 \%$.

Table 3. Self-Reported tasks versus time-motion data

\begin{tabular}{|c|c|c|c|c|c|}
\hline \multirow{2}{*}{ Task } & \multicolumn{2}{|c|}{ Self-report (\%) } & \multicolumn{2}{|c|}{ Time-motion (\%) } & \multirow{2}{*}{$\begin{array}{c}\text { Difference (\%) } \\
\text { Means }\end{array}$} \\
\hline & Means & $S D$ & Means & $S D$ & \\
\hline \multicolumn{6}{|l|}{ Physician } \\
\hline Direct patient care & 49.3 & 12.8 & 15.1 & 5.5 & 34.2 \\
\hline Indirect patient care & 29.7 & 4.5 & 54.4 & 19.1 & -24.7 \\
\hline Education & 0 & 0 & 15.3 & 19.1 & -15.3 \\
\hline Personal & 10.5 & 2.4 & 2.2 & 2.3 & 8.3 \\
\hline Miscellaneous & 10.5 & 8.9 & 13 & 10.4 & -2.5 \\
\hline \multicolumn{6}{|l|}{ Physician Assistant } \\
\hline Direct patient care & 51.6 & - & 17.0 & 11.1 & 33.7 \\
\hline Indirect patient care & 31.5 & - & 54.2 & 23.2 & 13.6 \\
\hline Education & 0 & - & 7.4 & 16.5 & -7.4 \\
\hline Personal & 12.1 & - & 8.2 & 17 & 3.9 \\
\hline Miscellaneous & 4.8 & - & 12.3 & 7.5 & -7.5 \\
\hline
\end{tabular}

On a daily basis, the PA spent an average of $54 \%$ of the time on indirect patient care and the majority of this time was spent on patient encounter documentation. Direct patient care tasks were recorded much less often. The PA spent nearly $28 \%$ of her time on education, personal tasks, and miscellaneous tasks combined. The tasks recorded most often for the PA were documentation (32\%), examinations, procedures, and follow-up (18\%). Family meetings and writing orders were recorded the least for the observed PA.

On average the physicians spent $55 \%$ of their workday on indirect patient care, primarily documentation. For the 
physicians direct patient care tasks were recorded less often whereas education tasks were observed more often. Personal tasks were rarely observed (2\%-4\%) and miscellaneous tasks comprised about one-tenth of the day. Documentation and professional development tasks were recorded most often for the physicians. The tasks MDs spent the least amount of time on were family meetings, personal tasks, and reviewing results.

Table 3 shows a side-by-side comparison of the self-report findings and the time-motion data. The difference in mean percentages is also displayed. Direct patient care is the largest difference between perceived time and actual time spent on these tasks for both the physician and the PA. Both providers believed they spent approximately one-third or more of their workdays on direct patient care than the actual observations revealed. Also, neither provider marked education as a daily task in the self-report questionnaire. It was determined in the time-motion data that physicians spent $15 \%$ of their day and the PA spent $7 \%$ of her day on education (professional development and teaching).

The results from the self-report survey showed that each provider felt they spent approximately one-half of his/her day on direct patient care when the actual time spent on direct patient care for both providers was less than $20 \%$. The results suggest hospitalists, at least in this hospital, spend most of their day on indirect patient care (documentation, reviewing results, communicating, and writing orders).

\section{Discussion}

A number of observations emerged from this project: the MDs' limited understanding of the PA role, how PAs can augment physician workload, and how perception and reality differ when viewing each other's role (as well as their own). All four hospitalists overestimated what they did and underestimated what the others did in the same task. In fact, across all four clinicians, each thought they spent more time than they did on direct patient care when it was actually onefifth of their daily activity. So routine was each observed session that "saturation" was quickly reached after the first two weeks of observation (saturation is the point in data collection when no new or relevant information is gained).

Physician misunderstanding of the role of the PA was first noted in the 1980s. One study found that the physicians' perception of what PAs could do varied widely, between $29 \%$ and $46 \%$, when, in fact, the activities were chosen from a list of the most commonly performed activities PAs were already doing. ${ }^{[6]}$ In one hospital study involving physicians, PAs and NPs the tasks are shared more than delegated and labor not divided by training. ${ }^{[7]}$

Published by Sciedu Press
The rise of hospitalists in American medicine has a close history with the rise of PAs: decreasing workload of "house staff' due to work-hour restrictions, and the increasing employment of PAs and NPs in hospital roles. ${ }^{[8]}$ It is this hospitalist role where PAs may be especially effective as team members. Singh found that inpatient care provided by physician-PA hospitalist teams was associated with a $7 \%$ longer length of stay (LOS) than resident-physician only but readmission and inpatient mortality similar to resident-based teams. The increase in LOS was dependent on the time of admission of the patients. ${ }^{[9]}$ In another study total cost of care was lower on the study service, but LOS was not different when as compared with house staff services. No difference was seen in inpatient mortality, ICU transfers, readmissions, or patient satisfaction. ${ }^{[10]}$ Evidence is accumulating that the role of PAs in hospitals can: improve patient care, fill shortages, be available during physician absence, improve resident training, and participate as a team member. Their labor cost alone makes this a viable fiscal option.

The situation on this territorial island was the same as in many locales throughout North America - medical workforce shortages have resulted in increased utilization and reliance on PAs. ${ }^{[10-12]}$ That hospitalists improve care overall regardless of the type of clinician is increasingly evident. ${ }^{[13]}$ Their role in small hospitals, rural hospitals, and island-isolated hospitals is unique, unknown, and needs further study.

This study sets the stage for a broader project involving PAs, NPs, multiple hospitals, and multiple roles. Both qualitative and quantitative analysis of providers and administrators is needed to understand the complexity of these actors at a time of growing medical provider scarcity, aging population, and a growing census of hospital beds.

\section{Limitations}

There are limitations: a study of this nature should be viewed with the understanding that a broad-based one, randomly controlled, with cross over design, on a small island was not possible and, instead, a convenience sample was selected necessity dictated such. With only one hospital that is significantly understaffed, the best study under the circumstances was a committed one to control as many variables as possible. Perhaps PAs in other locations engage in more direct patient care and are utilized more fully than the one observed in this study but such information remains unpublished.

As an administrative research activity the process differs from those guided by research questions that are hypothesis driven. Because administrative studies in healthcare looks for centralization and human values it is often the first step for laying the groundwork for more probing types of analysis 
such as financial, social, outcomes, and economic types of health services research. In that sense the project met its goal. The results of this study are more general in nature and may not be applicable to PAs practicing in specialty services.

\section{Conclusion}

Inadequate medical staffing compounds health care disparities in far-flung hospitals. Newer enabling US territorial legislation has also permitted the utilization of PAs and NPs in various roles. The introduction of a PA to supplement the hospitalist corps at the St. Croix hospital offered an opportunity to examine what tasks could be transferred and how physician hospitalists perceived this role. The result was an extensive list of care services and similarity in broad-based tasks. It also revealed a gap among what hospitalists perceived of each colleague's labor and what actually occurred on their appointed rounds.

\section{ACKNOWLEDGEMENTS}

Special thanks to the Governor Juan F. Luis Hospital \& Medical Center and administrators for welcoming the researchers and the clinicians who graciously chose to participate in the study.

\section{Conflicts OF InTEREST Disclosure}

The authors declare they have no conflict of interest.

\section{REFERENCES}

[1] Ziller E. Access to medical care in rural America. Rural Public Health: Best Practices and Prevention Models. Warren JC, Smalley KB, Eds. New York, NY: Springer Publishing Company; 2014. 11-28.

[2] Kaufman NJ, Castrucci BC, Pearsol J, et al. Thinking beyond the silos: Emerging priorities in workforce development for state and local government public health agencies. Journal of Public Health Management and Practice. 2014; 20(6): 557. PMid: 24667228. http://dx.doi.org/10.1097/PHH.0000000000000076

[3] Krein SL. The employment and use of nurse practitioners and physician assistants by rural hospitals. The Journal of Rural Health. 1997; 13(1): 45-58. PMid: 10167765.

[4] Thorpe-Jamison PT, Culley CM, Perera S, et al. Evaluating the impact of computer-generated rounding reports on physician workflow in the nursing home: A feasibility time-motion study. Journal of the American Medical Directors Association. 2013; 14(5): 358-62. PMid: 23318665. http://dx.doi.org/10.1016/j.jamda. 201 2.11 .008

[5] Weigl M, Müller A, Zupanc A, et al. Participant observation of time allocation, direct patient contact and simultaneous activities in hospital physicians. BMC Health Serv Res. 2009; 9(1): 110. PMid: 19563625. http://dx.doi.org/10.1186/1472-6963-9-110

[6] Johnson RE, Freeborn DK. Comparing HMO physicians' attitudes towards NPs and PAs. Nurse Pract. 1986 January; 11(1): 9-49. http://dx.doi.org/10.1097/00006205-198601000-00006

[7] Gershengorn HB, Wunsch H, Wahab R, et al. Impact of nonphysician staffing on outcomes in a medical ICU. CHEST Journal. 2011; 139(6): 1347-53. PMid: 21393397. http://dx.doi.org/10.13 78/chest. 10-2648
[8] Cawley JF, Hooker RS. The effects of resident work hour restrictions on physician assistant hospital utilization. J Physician Assist Educ. 2006; 17(3): 41-3. http://dx.doi.org/10.1097/01367895-2 00617030-00008

[9] Singh S, Fletcher KE, Schapira MM, et al. A comparison of outcomes of general medical inpatient care provided by a hospitalistphysician assistant model vs a traditional resident-based model. J Hosp Med. 2011 March; 6(3): 122-30. PMid: 21387547. http: $/ / \mathrm{dx}$.doi.org/10.1002/jhm.826

[10] Roy CL, Liang CL, Lund M, et al. Implementation of a physician assistant/hospitalist service in an academic medical center: Impact on efficiency and patient outcomes. J Hosp Med. 2008 September; 3(5): 361-8. PMid: 18951397. http://dx.doi.org/10.1002/j $\mathrm{hm} .352$

[11] Zwijnenberg NC, Bours GJ. Nurse practitioners and physician assistants in dutch hospitals: Their role, extent of substitution and facilitators and barriers experienced in the reallocation of tasks. $\mathbf{J}$ Adv Nurs. 2012 June; 68(6): 1235-46. PMid: 21899594. http: //dx.doi.org/10.1111/j.1365-2648.2011.05823.x

[12] Kleinpell RM, Ely EW, Grabenkort R. Nurse practitioners and physician assistants in the intensive care unit: An evidence-based review. Crit Care Med. 2008 October; 36(10): 2888-97. PMid: 18766097 http://dx.doi.org/10.1097/CCM.0b013e318186ba8c

[13] Diamond HS, Goldberg E, Janosky JE. The effect of full-time faculty hospitalists on the efficiency of care at a community teaching hospital. Ann Intern Med. 1998 August; 129(3): 197-203. PMid: 9696727. http://dx.doi.org/10.7326/0003-4819-129-3-1 99808010-00006 